\title{
Enfoques teóricos y usos políticos del concepto de espacio público bajo el neoliberalismo en la ciudad de Cuernavaca, México
}

Theoretical frameworks and political uses of the concept of public
space under neoliberalism in the city of Cuernavaca, Mexico

Carla Alexandra Filipe Narciso

\section{Resumen}

Dentro de la construcción de la ciudad neoliberal, el espacio público se ha convertido en un concepto central y de uso generalizado en los discursos y las agendas académicas y políticas. Su uso se ha tornado polisémico, ideologizado e incluso altamente idealizado cuando se trata de legitimar la ordenación capitalista de las ciudades y de ocultar las desigualdades sociales que generan dichas intervenciones. ¿Cómo y para qué sirve al Estado y a los gobiernos neoliberales el concepto de espacio público? La respuesta a esta pregunta se desarrolla a lo largo del documento a través de un estudio de carácter cualitativo cuya metodología es comprender e interpretar para poder transformar (Massey, 1984).

Palabras claves: espacio público; gobierno neoliberal; ideología política; diferenciación social; relaciones socioterritoriales.

\begin{abstract}
In the construction of the neoliberal city, public space has become a central concept with widespread use in academic and political discourses and agendas. Its utilization has become polysemic, ideological, and even highly idealized when it comes to legitimizing the capitalist management of cities and hiding the social inequalities that generate such interventions. What is the use of the concept of public space to the State and to neoliberal governments and how do they use it? The answer to this question is developed throughout the paper through a qualitative study whose methodology is to understand and interpret in order to transform (Massey, 1984).
\end{abstract}

Keywords: public space; neoliberal government; political ideology; social differentiation, socioterritorial relations. 


\section{Introducción}

El estudio del espacio público ha sido en los últimos años un tema de persistente debate entre diversas disciplinas, sin embargo, en él se mantiene una cierta confusión en relación con su significado y dimensión, ya que comúnmente se refiere a una extensión abstracta de uso común con el que se designa espacio político, opinión pública, vida pública, ciberespacio, dominio público y espacios físicos, en el caso concreto a describir, las plazas. La evolución conceptual de los conceptos mencionados ha dado como resultado el que sean tratados como sinónimos dentro de un marco neoliberal, es decir, hablar de plaza es lo mismo que hablar de dominio público o espacio democrático de la toma de decisiones de la comunidad. Sin embargo, hay que tener en cuenta que la selección léxica que se haga no es neutral, está repleta de significados, ideologías y de legitimización social de los mismos poderes gubernamentales. Esa inercia abstracta del concepto procura justificar las intervenciones del gobierno que no hacen más que aumentar las desigualdades sociales a través de una deformación u ocultamiento de la realidad que hace creer a las clases dominadas que participan del mismo modo en la sociedad, mientras las hegemonías se van tornando cada vez más fuertes. Como comenta Delgado (2011, p. 25), "(...) la dominación no solo domina, sino que también dirige y orienta moralmente tanto el pensamiento como la acción sociales". Lo preocupante es que la validez de estos discursos está respaldada por la misma academia y viceversa, así como de organizaciones nacionales e internacionales.
Pero, ¿cómo viven y entienden las poblaciones estos espacios ideológicos?, ¿cuál es la relación entre la forma de las relaciones socio-territoriales y las nociones de espacio público que construyen los agentes, enfatizándose el uso y apropiación que se desarrolla en los lugares, así como la percepción que de estos se derivan de forma conjunta y complementaria en la ciudad de Cuernavaca? Estas preguntas orientan el presente trabajo, justificado por el conocimiento sobre el espacio público de Cuernavaca y cómo este fue rompiendo y cuestionando con ideas y teorías predeterminadas que no se aplican al espacio en estudio y cuya definición puede estar conformada por distintos supuestos teóricos asociado a diferentes factores, en la mayoría de los casos, contextos abstractos y homogéneos. Así, ¿cómo ubicarse fuera de los cánones producidos para pensar de otra forma el espacio público? Nuestro objetivo es generar conocimiento y teoría a partir del caso empírico de Cuernavaca, a partir de los agentes que usan, perciben y se apropian del espacio público.

En esta labor asumimos el concepto de lugar como lugar de identidad y de percepción, pero también como una integración de espacio y tiempo, como un tejer de historias en proceso, como un momento dentro de las geometrías del poder y, en proceso, una tarea inacabada (Massey, 2008). Además, si es una tarea inacabada y en contante construcción, ¿cómo se puede seguir hablando de un espacio público en abstracto y que se territorializa de la misma forma en cualquier contexto? Es esa misma concepción del espacio público y como se ha viniendo construyendo que hace que se haya tornado un blanco por excelencia del 
poder político, ya que su carácter impreciso y mítico lo ha convertido en un discurso repleto de ideales e ideologías.

El trabajo se estructura en cinco partes: en la primera, haremos un breve recurrido por la evolución conceptual del espacio público y su correlación con la construcción histórica en la ciudad de Cuernavaca; en la segunda parte concretamos el análisis a partir de la nueva corriente neoliberal y cómo se manifestó en la ciudad; la tercera parte se dedica a analizar las relaciones que los agentes construyen en los lugares concretos a partir de sus prácticas cotidianas; posteriormente, en la cuarta parte, analizamos la forma en que los agentes perciben y representan el concepto; finalmente, ponemos a discusión esa relación con el poder político.

\section{La contracara de la concepción teórica del espacio público en la ciudad de Cuernavaca}

Tradicionalmente, el espacio público fue creado o definido como lugar de expresión política y social, de interacción y modos de la vida cotidiana de una sociedad, que se expresaba igualitaria desde una perspectiva teórica. Este marco de análisis surge en la modernidad a partir de los escritos filosóficos de Habermas (1984) y Arendt (1972) que cuestionan la dimensión pública y privada (esfera pública) del espacio público y que, posteriormente, se ha tornado en uno de los principales marcos para su discusión. A pesar de que estos autores no hayan discutido el desarrollo del concepto de espacio público como tal, la conformación histórica con la que analizan la esfera pública se volvió un sello imperativo en el análisis del concepto como espacio de la ciudadanía y de la expresión igualitaria del poder y de los derechos comunes. Habermas (1984) y Arendt (1972) retoman la esfera pública y privada de la civilización romana y griega respectivamente, configurados a partir del ágora y el fórum, donde el ciudadano libre y los señores feudales ejercían su poder. Arendt (1972) define el espacio público a partir de una concepción de carácter más simbólico como el espacio de las apariencias, la expresión de modos de subjetivación no identitarios, en contrapunto a los territorios familiares y de identificación comunitaria, pero donde rige la libertad y la igualdad. Habermas (1984), por su parte, define lo público como consecuencia y prolongamiento de las relaciones económicas; como el dominio histórico construido a partir de la controversia democrática y finalmente como el espacio de uso libre y público de la razón. La postura de Habermas fue tomada de Kant que defendía que el espacio público estaba en el corazón del funcionamiento democrático, así como la esfera intermedia que se constituyó históricamente, en el período de las Luces, entre la sociedad civil y el Estado.

Entonces, el espacio público sería el lugar accesible a todos los ciudadanos, donde el público se reunía para formular una opinión de forma democrática. La posición de Habermas lleva a la construcción de un espacio público idílico que supone la existencia de individuos más o menos autónomos, con capacidad de formar una opinión propia, no "alienados a los discursos dominantes", acreditando en las ideas, argumentos y no solamente en la confrontación física. En este contexto, el espacio 
público sería la autenticidad de las palabras que se impone sobre la de los muros, de las vanguardias y de los sujetos de la Historia; la idea de un reconocimiento del otro y no su reducción al estado de "sujeto alienado"; el reconocimiento del otro como igual y no como diferente, lo que irreflexivamente marcaba las pautas de definición entre público y privado.

Parece ser, en efecto, que era la redefinición de lo privado lo que permitía al espacio público diseñarse y afirmarse, en contrapunto, pero siempre en función de grupos hegemónicos. La definición de los límites entre los espacios públicos y privados era clara y acentuada por el uso de clase, factor que, de acuerdo a algunos autores, parece que se ha perdido en varios momentos de la historia. ¿Será que realmente se ha perdido o es un elemento que efectivamente lo define? Las aportaciones de Habermas (1984) y Arendt (1972) y su marco de análisis entre esfera pública y privada hacen que, a partir de los años setenta aproximadamente, el análisis político del espacio público se popularice y gane especial relevancia en su teorización. Lo anterior ha llevado a la acepción de espacio público como aquel que, adentro del territorio urbano tradicional, sobre todo en las ciudades capitalistas, donde la presencia del sector privado es predominante, es del uso común y posesión colectiva, pertenece al poder público y como tal existe para el uso común donde todos tienen derecho.

Esta imagen idealizada de un espacio público moderno se ve afectada por diversos cambios urbanos, sobre todo desde una lógica neoliberal que acentuó procesos de fragmentación y privatización. A partir de esto, desde diferentes latitudes geográficas autores como Sennett (1978); Borja (2003); Giglia (2003); Zukin (2010) y Ramírez Kuri (2009) empiezan a reivindicar el espacio público como construcción social y como elemento activo en la comprensión de las relaciones y prácticas sociales en que se especializan, transformando tanto la estructura, la forma y la imagen urbana como las actividades humanas y el significado de la ciudad vivida por grupos y actores sociales diferentes.

Las aportaciones de estos últimos autores surgen de la confrontación con la planificación y su cambio de intervención funcional a intervención espectáculo y monumental, sumándose aquí la proliferación de los centros comerciales, condominios cerrados, pero también por la implementación de políticas urbanas que fomentan los grandes proyectos de renovación que han originado una pérdida de la identidad y sociabilidad, la generación de procesos de exclusión, la privatización de la vida urbana y la desigualdad social (Caldeira, 2007; Low, 2005) despuntando la crisis y muerte del espacio público (Borja, 2005; Davis, 1992; Sorkin, 2004; Duhau y Giglia, 2008). Sin embargo, esta crisis se ha cuestionado en el sentido que algunos rasgos de la sociedad actual ya se observaban en la sociedad moderna: la desigualdad social, la segregación y fragmentación urbana. ¿Entonces, hasta qué punto estas transformaciones urbanas han detonado una crisis del espacio público?, ¿cuáles son los objetivos de estas transformaciones y su relación con la modernidad? Lo que podemos afirmar es que este tipo de transformaciones urbanas son resultado de un amplio proceso de reproducción de las relaciones de producción capitalistas y de la necesidad del capital en 
generar excedente. En la modernidad podían ya observarse, pero con otros matices.

Lo que nos parece pertinente considerar es el supuesto desde el que dirigimos la investigación: más que una crisis del espacio público hubo dos transformaciones clave, por un lado, una refuncionalización a partir de las nuevas estructuras urbanas controladas por nuevos agentes como el poder municipal y el mercado; y, por el otro, una resignificación a partir del momento que el espacio público se asume como un producto que puede ser comercializado desde el ideario de las clases hegemónicas.

Ahora, esta crisis del espacio público levantó diversos cuestionamientos sobre su papel en la ciudad y el debilitamiento de los espacios de formación de la sociedad, de inclusión social, de accesibilidad y movilidad que se estaban generando. Se empezó, entonces, a problematizar a nivel mundial sobre la importancia de espacios dignos para la convivencia y calidad de vida en condiciones de igualdad, es decir, sobre la cuestión del derecho al espacio público como un derecho humano.

Hablar del derecho al espacio público es hablar de los atributos tangibles e intangibles del espacio público que han sido defendidos por diversos autores e instituciones (DGOTDU - Direcção Geral do Ordenamento do Território e Desenvolvimento Urbano, 2008; www.pps.org; Unesco) como la accesibilidad, el confort, la buena imagen y el entorno amigable, perspectiva asociada en cierta medida a arquitectos y urbanistas. Entonces, si el adjetivo público evoca a una accesibilidad generalizada e irrestricta, un espacio accesible a todos debe significar algo más que simple acceso físico a espacios abiertos de uso colectivo, debe ser un componente fundamental para la organización de la vida colectiva (integración, estructura) y de representación (cultura, política) de la sociedad que construye su razón de ser en la ciudad. Por otra parte, el segundo atributo que se defiende como el derecho al espacio público es el derecho a espacios públicos confortables y con buena imagen ${ }^{1}$ que promuevan la inclusión social (Carrión, 2007) aunque se pueda generar segregación social porque los espacios bonitos son para las zonas de ingresos medios/altos y para las zonas de ingresos bajos, "cualquier cosa sirve". Estas alocuciones denotan cierta ambigüedad y recaen sobre clichés preestablecidos y homogéneos propios de un discurso neoliberal.

La componente idílica transversal al espacio público heredada de la modernidad se empieza a cuestionar desde diferentes posiciones académicas ya que el neoliberalismo lo va a detonar como un elemento estructurador y vertebrador del territorio de la ciudad, entendido como el espacio físico y las funciones urbanas que en él se procesan. El espacio público moderno era una garantía de las continuidades que incluía en la ciudad las áreas segregadas y acercaba la periferia con el centro. En estos discursos, el espacio público surge como el espacio por excelencia de y en la ciudad, es el espacio en el cual se conoce la ciudad, capaz de producir ciudad y generar integración social (Carrión, 2007; Borja, 2003; Ramírez Kuri, 2009; Jacobs, 1992).

Borja (2003) explica que los valores vinculados a la ciudad - libertad y cohesión social, protección y desarrollo de los derechos individuales y expresión y construcción 
de identidades colectivas, de democracia participativa y de igualdad básica entre sus habitantes - dependen de que el estatuto de ciudadanía sea una realidad material y no solamente un reconocimiento formal. Pero, ¿qué es la ciudadanía o de cuál ciudadanía nos habla? Parece ser una definición muy abstracta (Delgado, 2011) la que Borja ofrece, además, existen dimensiones importantes como la política, temporal e histórica que no son consideradas.

Por otro lado, el origen de la crisis del vínculo social y de la crisis de ciudadanía que Borja (2003) argumenta parece estar en la pérdida de los valores (democrático) que otorga al espacio público, así como de su función relacional que, según el autor, parece ser que no aísla, no segrega a los habitantes, pero les da la oportunidad de vivir y participar en igualdad en la ciudad. ¿Pero hasta qué punto el espacio público se caracteriza por ser democrático e igualitario?, ¿dónde está la democracia y la igualdad? Nuestra posición es diferente de Borja y más cuando consideramos casos empíricos sobretodo de ciudades en Latinoamérica cuyas realidades son muy diferentes en que la construcción del espacio público ha generado desigualdades sociales muy fuertes, ${ }^{2}$ como el caso de Cuernavaca. Por otra parte, autores como Fainstein (2005) tejen toda una crítica a esta conceptualización del espacio público, argumentando que este nunca fue democrático, ya que no todos participaban en los fórums y ágoras del mismo modo, incluso había gente, sobretodo de las clases bajas, que no podían asistir. Entonces, ¿dónde está la democracia perdida?
También Ash Amin (s. d.) cuestiona las actuales posturas sobre el espacio público, para el autor no se puede pensar más como un sitio central de la formación política. Se está lejos de los tiempos cuando los espacios públicos de la ciudad central eran un sitio político primordial. Sin embargo, aunque nos parece pertinente la posición de Amin, el autor no hace un análisis más específico de la historia y también cree en un espacio idílico de integración social, en que todos participaban por igual. A pesar de su crítica dura, Amin no puede imaginar un lugar desde proyecciones comunes del espacio público porque los diferentes contextos tienen representaciones diferentes. Efectivamente, aunque se construyan bajo procesos similares, los matices en los que se reproducen espacialmente son distintos. Para Amin, el verdadero público son los espacios públicos de la calle, de la plaza, del jardín, del centro comercial, pero también los virtuales.

Parece así que estamos frente a un espacio público con nuevos significados - político, ideológico, social y estructural pensado como un recurso, un producto y una práctica (cotidiana, política, simbólica).

Desde las distintas posiciones - las que reivindican la dimensión pública o la física - las perspectivas de análisis se han ido entrelazando, la dimensión pública se vuelve espacial y viceversa, lo que ha dificultado más su conceptualización, convirtiéndolo así en un discurso ideal e ideológico o "una práctica entendida como una unidad o incluso como una política dominada por una misma perspectiva". ${ }^{3}$ Como bien señala Delgado (2011, p. 10): 
[...] el espacio público pasa a concebirse como la realización de un valor ideológico, lugar en el que se materializan diversas categorías abstractas como democracia, ciudadanía, convivencia, civismo, consenso y otros valores políticos centrales, un escenario en el que se desearía ver deslizarse a una ordenada masa de seres libres e iguales que emplea ese espacio para ir y venir de trabajar o de consumir y que, en sus ratos libres, pasean despreocupados por un paraíso de cortesía.

Esa construcción ideológica lo ha definido a partir de un espacio contenedor que parece ser igual y que se define en todos los lugares de la misma forma, esto es, la experiencia entre diferentes, la posibilidad de encuentro entre desiguales, la interacción e integración social, la vivencia de la ciudad a partir del espacio son procesos comunes a cualquier espacio público. Es en cierta medida a partir de esta idea del espacio público contenedor y reflejo, que autores como Lefebvre (1974) y, posteriormente, Santos (1986) y Massey (2005) proponen incorporar nuevas dimensiones sociogeográficas y a su vez renovar las perspectivas tradicionales sobre la conceptualización o significado de la categoría del espacio, propuesta que retomaremos para el análisis del espacio público. Así, a partir del análisis metodológico del espacio de Massey (2005) nos quedó claro que no podíamos analizar el espacio público de Cuernavaca como un objeto inanimado, sino como un objeto que está directamente relacionado con la conformación de la sociedad en sus distintos momentos históricos así como de las relaciones socioterritoriales que lo van resignificando y reutilizando. Así, ¿de qué espacio público estamos hablamos?

El espacio público de Cuernavaca a finales del siglo XIX era un espacio marcadamente dividido entre la clase baja y la aristocracia; había una clara división socioterritorial entre los espacios públicos que usaban las dos clases. Incluso el mismo uso era diferenciado, ya que no era lo mismo el uso por necesidad del trabajo cotidiano de las clases bajas, a los paseos de la aristocracia que se lucia por los espacios públicos emblemáticos de la ciudad. Esta dualidad fue acentuada con la llegada de Porfirio Díaz y la inauguración del ferrocarril que detonó diversas obras que transformaron el centro de la ciudad y expulsaron a los mercadores que conferían una "mala imagen" a las zonas centrales y obstruían la "belleza" de la ciudad.

El descontento con la administración del presidente Porfirio Díaz levanta la revolución y la ciudad de Cuernavaca es el palco por excelencia de confluencia de los ejércitos. Así, cuando el comando de Emiliano Zapata toma las calles, plazas y jardines de la ciudad de Cuernavaca, la aristocracia la abandona y solo a partir de los años veinte o treinta empieza a regresar, pero va encontrar en el espacio privado las funciones que anteriormente depositaba en el espacio público. Este periodo es marcado por una resignificación y refuncionalización del espacio público a través del abandono de los espacios públicos de las elites y la apropiación de espacios privados y una reapropiación de esos espacios por las clases bajas. El espacio público es así reconstruido a partir de la resistencia social y con funciones que sirven al mismo trabajo, las clases populares al ganar ese 
espacio lo refuncionalizan de acuerdo a sus necesidades que, por un lado, es la necesidad de reivindicación de derechos por la tierra, por el trabajo, pero también por el esparcimiento. En los años sesenta, Cuernavaca va a recibir mucha migración por cuenta de la implementación del complejo industrial, sobre todo del estado de Guerrero y empieza la disputa por las tierras entre los asentamientos irregulares y los fraccionamientos de lujo. Los diferentes grupos sociales (dentro de una misma clase social) empiezan a apropiarse de los diferentes espacios y a consolidarlos a partir de sus prácticas (uso, percepción y apropiación). Pero esa diferencia entre espacios es acentuada a partir de los años noventa cuando el proceso de privatización del espacio en Cuernavaca se realza con las políticas neoliberales y el surgimiento de las primeras plazas comerciales.

Este momento de privatización de la vida pública ${ }^{4}$ despunta un interés en el estudio sobre del espacio público, tornándose "el centro del debate sobre las políticas urbanas, al ser tomado como un componente urbano capaz de soportar o desencadenar otros procesos económicos y culturales" (Portas, 2003).

\section{¿Cómo se redefine y resignifica el espacio público en el nuevo orden económico neoliberal?}

Una nueva política se hacía adivinar por la aportación del intervencionismo estatal keynesiano que siguió a la Gran Depresión de los años treinta y por una economía de guerra cuyo objetivo era reconstruir las economías y resolver la consecuente crisis de acumulación (Pradilla, 2009). El proyecto neoliberal aparece así como una forma de lograr la restauración del poder de clase, pero que al mismo tiempo hacía más vivos " (...) los efectos redistributivos y la creciente desigualdad social como un rasgo tan persistente de la neoliberalizacion para poder ser considerado un rasgo estructural de todo el proyecto" (Harvey, 2007, p. 23). Esa reconfiguración en pro de la acumulación del capital se sienta en una política de empresarialismo urbano y de transferencia de la competencia de los estados a los municipios y al sector privado.

En este periodo la urbanización gana especial protagonismo como un anclaje espacializado por excelencia para acumulación y reproducción del capital. Sin embargo, autores como Pradilla (2009) argumentan que el urbanismo a escala urbana tiende a extinguirse, manteniéndose como débil instrumento de regulación mientras ganan importancia el capital inmobiliario y sus grandes proyectos urbanos o megaproyectos. Efectivamente, si consideramos la escala de la metrópoli y su importancia en el contexto global, vemos que muchos de los proyectos de renovación urbana y espacio público se reproducen de la misma forma en esas escalas, lo que significa que se convertirán en elementos de mercantilización.

Esta nueva forma de construir ciudad, y a su vez el espacio público, no hizo más que aumentar el número de condominios cerrados, el conservadurismo estilístico, la homogeneidad, una imagen general de intolerancia y el mote de reivindicación de 
un espacio público moderno inexistente. No se ofrecieron soluciones para problemas existentes, sino soluciones para las clases media y alta. ¿Qué es lo que actualmente hace la diferencia en el proceso de construcción social del espacio público?

En la tarea que el estado delega a los municipios, estos últimos se aprovechan $y$, conscientes de sus limitantes, empiezan a mostrar y mezclar una serie de intereses públicos y privados - que puede ir desde los intereses del propio presidente a agentes privados y a grupos sociales hegemónicos. Esa mezcla es visible en la reproducción del espacio de forma conflictiva, porque posiciona intereses contradictorios en donde gana lo que más puede.

En este contexto, las infraestructuras urbanas se vuelven imperativas para la acumulación y regulación neoliberal, incluso cuando en el proceso simultáneamente se las socava y devalúa: se coloca las ciudades en las fronteras de la formación de políticas neoliberales al tiempo que son lugares de resistencia concertada a la neoliberalización (Leitner et al., 2007).

En América Latina, la expresión territorial del neoliberalismo surge a partir del agotamiento de la industrialización sustitutiva de importaciones en la década de los setenta y de la entrada de la economía en la onda larga recesiva consecuencia de la grave crisis económica de 1982, lo que abrió la puerta política e ideológica a la progresiva implantación de las políticas neoliberales y al inicio de la extensión de la planeación urbana y del gran urbanismo (Pradilla, 2009, p. 206). Desde los años noventa, la lógica de mercado neoliberal se empieza a reflejar en las formas de producción y de gestión del espacio urbano, en los grandes proyectos inmobiliarios conducidos por el capital privado, en espacios públicos cerrados y controlados en forma privada, en el abandono de espacios públicos tradicionales por parte de las clases media y alta y la colonización de los mismos por los sectores populares, entre otros (Duhau, 2003).

Sin embargo, este no es un proceso nuevo, recordemos las intervenciones de Haussaman en París que, con el objetivo de sanear e higienizar la ciudad, confina las clases bajas a zonas marginadas y al uso del cuartier (Sennett, 1978) para que las clases burguesas pudieran disfrutar tranquilamente de las zonas bonitas de la ciudad sin mezclarse con las clases populares. Estas intervenciones fueron posibles gracias al apoyo de "la burocracia capitalina que incentivó la reconstrucción de París por Haussmann acumulación de capital" (Sennett, 1978), al igual que en México con la política económica del régimen porfirista.

La lógica de poder económico y de embellecimiento urbano de Porfirio Díaz también se trasladó a Cuernavaca, con las características de un contexto latinoamericano, mexicano, del centro del país, la ciudad de la eterna primavera. Lo anterior ha conferido al proceso neoliberal y a sus mecanismos de urbanización en la ciudad especificidades propias y seguramente muy distintas de otras ciudades. El gobierno de la ciudad dio continuidad y además profundizó las metas urbanas neoliberales definidas por Brenner et al. (2009), apoyadas por una clase dominante muy fuerte. En este nuevo proceso entra un nuevo agente, el mercado, y sale el Estado. La ciudad se queda a la merced del 
mercado, entra en la lógica de la privatización de los espacios: consumo de las elites (lo que ya ocurría pero de otra forma) y el control de poblaciones excluidas a diferentes escalas; promoción de políticas de marketing territorial; reducción de los impuestos locales; establecimiento de corporaciones públicoprivadas y nuevas formas de promoción local.

En 1991 es cuando el proceso gana mayores contornos con el surgimiento de la primera plaza comercial, Plaza Cuernavaca, que pretendía dar respuesta a los moradores de una de las zonas elegantes de la ciudad: Reforma y Vista Hermosa. En el año de 2001 se genera uno de los grandes conflictos en la ciudad debido a la construcción de una zona comercial en Casino de la Selva, lo cual llevó a la destrucción de una de las zonas naturales y culturales más importantes de la ciudad.

En 2005 se construye la Plaza Galerías junto de la autopista México-Cuernavaca, como una forma de dotar a las clases mediasaltas de espacios de consumo diferenciados de la Plaza Cuernavaca que se había popularizado. Actualmente se encuentra en construcción lo que será lo nuevo centro comercial en la Av. Domingo Diez, en la zona norte de la ciudad junto a Wal-Mart. Es visible cómo la construcción del espacio se lleva a cabo en buena medida en función del mercado y de la sociedad de consumo.

En 2009 surge el programa de embellecimiento de la imagen urbana ${ }^{5}$ de la ciudad de Cuernavaca, a través del cual el ayuntamiento, impulsor del proyecto, contrajo un préstamo bancario de 600 millones de pesos con el objetivo de movilizar la ciudad a la modernidad y desarrollo. El programa tenía beneficios integrales tales como dotar a la población de espacios dignos para la convivencia social, evitar el ocio y conductas antisociales, además de atraer al turismo y generar el desarrollo de la economía local. ${ }^{6}$ Más que por las intervenciones, este programa ganó importancia por los discursos políticos que lo concibieron como un referente sociourbano idílico, pero también una mercancía y un mecanismo de control utilizado como moneda de cambio para propósitos electorales.

Las obras llevadas a cabo tuvieran como blanco de intervención glorietas y camellones (principal tipología en que intervinieron), sobretodo en áreas de ingresos mediosaltos y altos o ejes estructurales de la ciudad como Av. Domingo Diez y Av. Morelos. Su principal característica fue adornar con flores y fuentes repitiendo una imagen similar de composición espacial en las diversas obras. Dentro del programa se destacan dos obras cuya implementación tiene relevancia por los objetivos y discursos que las acompañaran: la primera fue el Parque Tlaltenango, ya que no fue una determinación del alcalde sino de un grupo de agentes de clase media-alta que buscaba su propio espacio, marcando las pautas de acceso y automáticamente excluyendo a los moradores de una colonia popular colindante. La paradoja es que, en los discursos, este era un parque resultado de la "ciudadanía".

El segundo ejemplo fue la construcción de la "Fuente de la Eterna Primavera y sus Cinco Musas" en la Avenida Teopanzolco que, de acuerdo con el nuevo alcalde Sánchez Gatica, "será un símbolo, una referencia y un icono (...) situando a la Ciudad de la Eterna Primavera como un símbolo emblemático a 
nivel mundial". ${ }^{7}$ El discurso del alcalde es respaldado por el diseñador y arquitecto $^{8}$ de la obra, Carlos Benítez Fuentes,

Cuernavaca no es la excepción en cuanto a la necesidad de contar con espacios dignos de convivencia social. El programa (...) ha logrado este objetivo y si hoy involucramos a las bellas artes como elemento significativo, definiéndolas como un fenómeno social, un medio de comunicación, una necesidad del ser humano de expresarse y comunicarse mediante formas, colores, sonidos y movimientos, logramos una simbiosis de estas bellas artes, la arquitectura y la escultura,

señaló. ${ }^{9}$ Se unen así discursos ideológicos a partir de la cultura, como una forma engañosa de estimular la condición de exclusión de algunos agentes. Por otra parte, un factor muy interesante y que respalda lo anterior es que al término de cada obra se hacía una inauguración, pero no todas las fiestas eran iguales ya que los agentes eran distintos, estas se establecían de acuerdo a la clase social. La inauguración del camellón de la Av. Reforma (zona de ingresos altos) fue muy distinta del distribuidor vial de Emiliano Zapata donde distribuyeron comida y llevaron grupos musicales, lo que llevó a una espantosa afluencia de gente de colonias populares.

¿Entonces, de qué espacio público hablan los agentes públicos? Es visible cómo en este marco neoliberal la planificación anda de la mano con los discursos políticos y viceversa, pero también con los privados y los discursos académicos. Sin embargo, este tema ha sido abordado de forma distinta entre los diferentes autores, que en algunas ocasiones contradicen sus posturas. Aunque sea considerado para muchos un académico, autores como Borja (2005, pp. 16-17) han tenido un papel fundamental en la función pública y en las decisiones políticas, así que no es de extrañar que para él:

La presentación de las ciudades como lugares nodales, las nuevas oportunidades de los territorios (argumento apoyado en emergencias y reconversiones exitosas) y la prioridad al posicionamiento en las redes globales y, en consecuencia, a su proyección exterior han sido elementos clave de la construcción del vademécum de la buena política urbana. El plan estratégico, a su vez, ha sido la herramienta operativa (o ha pretendido serlo) de las ciudades aspirantes a triunfar en el mundo global mediante el discurso "hipercompetitivo»".

Para el autor, el urbanismo neoliberal debe ser encarado como una forma positiva de atraer inversión, de mercantilización de los espacios, y esa postura está apoyada por la misma mercantilización del modelo Barcelona a varios países de Latinoamérica, del cual Borja formó parte. Hay que resaltar las interesantes aportaciones que ha ofrecido al estudio del espacio público desde un punto de vista más conceptual, aunque muchas veces con discursos contradictorios, entre la academia y la función pública.

Borja y Forn (1996) creen que el mayor desafío del planeamiento urbano contemporáneo es aumentar el potencial competitivo de las ciudades en el sentido de responder a las demandas globales $\mathrm{y}$ atraer recursos humanos y financieros internacionales, sin embargo, de acuerdo con varios ejemplos que hemos observado, el planeamiento ha sido hecho al margen de 
la ciudad, en paralelo con los objetivos del capitalismo neoliberal. Su discurso es similar al del alcalde Garrigós de Cuernavaca en el sentido de magnificar las intervenciones en el espacio público como forma de regenerar la ciudad y tornarla competitiva. Aunque ya en la academia, él mismo acaba por reconocer que estos proyectos de renovación urbana como proyectos políticos de ciudad pueden "derivar en una cortina de humo llena de buenas intenciones sin otra función que legitimar las practicas del poder" (Borja 2005, p. 17).

Es importante referir en este contexto que las formas de reproducción de las políticas neoliberales no han sido siempre las mismas, sino que hubo una reconstitución del urbanismo neoliberal. Sin embargo, para la ciudad de Cuernavaca ha sido un proceso tardío que ha tenido su mayor auge en el siglo XXI. El imperativo neoliberal básico de movilizar el espacio económico como arena para el crecimiento capitalista, para la conversión de bienes y servicios en mercancías y para implantar la disciplina de mercado se ha mantenido como el proyecto político dominante de los gobiernos locales ( Brenner et al., 2009). Lo que se ha hecho es introducir el pensamiento estratégico y empresarial a la esfera de la administración urbana, donde consultores "estrategas" difunden la propuesta de que características del paisaje urbano deben ser utilizadas como uno de los principales triunfos en la competencia por recursos e inversiones.

Este tipo de intervenciones alienadas de su contexto, parece reducir los lazos de sociabilidad, de integración social, de no identificación, además del abandono y pérdida de la ciudadanía por un encarcelamiento de las personas en el ámbito doméstico. ¿Pero, hasta qué punto es correcta esta afirmación? ¿Se ha abandonado el Zócalo de Cuernavaca, o el Jardín San Juan, o el Jardín Juárez? Parece que no, e incluso en un clima de tanta violencia como el que vive la ciudad de Cuernavaca habría muchas razones para este retraimiento de los ciudadanos, pero los espacios siguen vivos. Eso pasa porque estas obras están pensadas para las clases altas de manera que los espacios de las clases bajas siguen teniendo "vida". Frente a esto, consideramos que este modelo de intervención lo que sí ha hecho, a través de las nuevas formas urbanas que generó, fue aumentar las desigualdades y disparidades entre la sociedad y bifurcaciones extremas entre la riqueza y la pobreza (Smith, 2005).

En este contexto de grandes cambios urbanos, el neoliberalismo implicó la redefinición de los conceptos, de forma que autores menos ortodoxos empiezan a plantear la veracidad o redundancia de los mismos (Ramírez, 2010), entre ellos el espacio público ya no como un contenedor, sino como una construcción de interrelaciones e interacciones en respuesta al espacio absoluto y abstracto (sin historia), pero que va más allá de su producción idílica.

Frente a este proceso de reestructuración y reconceptualización no podemos dejar de cuestionarnos: ¿qué representa y cómo se define actualmente el espacio público de Cuernavaca?, ¿cómo se dan las relaciones socioterritoriales en los lugares y su concordancia con los discursos políticos y académicos? 


\section{Construyendo nuevas geografías}

Lo valioso de una investigación de índole cualitativa es que son los mismos agentes entrevistados quienes generaran la base teórica para que uno pueda argumentar o disuadir los diversos planteamientos generales sobre el tema en cuestión. La aplicación de la teoría fundamentada nos permitió hacer un análisis comparativo y construir tipos u orientaciones de lugares, pero también poner en cuestión el concepto de espacio público desde el punto de vista de cómo lo entienden los agentes y cómo entienden su relación con el poder político. Así, a partir de criterios tales como localización, periodo sociourbanístico, agentes, prácticas, grupos de apropiación, orden público y orden urbano destacamos elementos como la colonia, el entorno, el contexto de construcción, la edad, la clase social, el nivel de estudios, el lugar de origen de los agentes, el uso, la percepción y la apropiación, las relaciones socioculturales, las relaciones entre grupos y su posición en el espacio y, finalmente, la localización en los diferentes tipos de ciudad. Así, con base en los criterios prestablecidos y los elementos que queríamos destacar en nuestra investigación con el afán de comprender las prácticas en el espacio público, elegimos la Plazuela del Zacate, el Parque Cri-cri y las Galerías Cuernavaca. ${ }^{10}$

Mapa 1 - Localización en la estructura urbana de los tres laboratorios de análisis a partir de la delimitación por Ageb

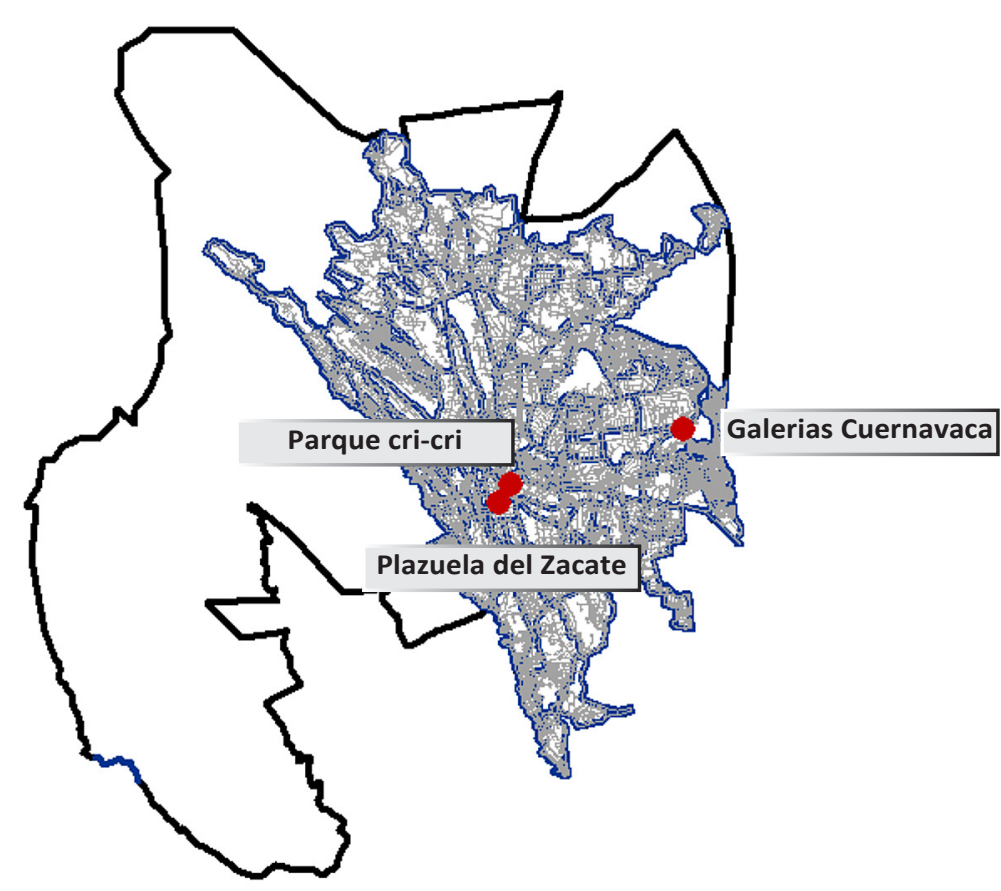


Para cada espacio público procedemos al levantamiento de entrevistas semiestructuradas a los distintos agentes que se encontraron. De esta forma nos fue posible determinar qué fenómenos estaban ocurriendo en los lugares en un contexto urbano como Cuernavaca, así como la relación que los agentes tienen con el espacio público y el poder político.

El espacio público concreto

"Generalmente es un espacio en el cual solo atrae a jóvenes a venir echar música fuerte y tomar alcohol" (Mujer, 24 años, Colonia La Pradera, Preparatoria). ¿Qué pasa en Plazuela del Zacate? Plazuela es caracterizado por ser un lugar de copas, de cervezas y de borrachos, su público blanco es mayoritariamente joven con un nivel de escolaridad media de licenciatura. La presencia de los bares es asumida, por un lado, como un espacio agradable de convivio y encuentro entre los jóvenes pero, por otra parte, refleja una imagen de violencia y vicio, lo que para algunos agentes (sobretodo personas de mediana edad o mayores) no convida a su disfrute; simplemente es un lugar de paso pues conecta dos paradas importantes de rutas, aunque hay quien dé la vuelta para no cruzar.

La presencia de los bares y las frecuentes alusiones a su representación como un factor denigrante del lugar es algo común entre los diversos agentes, sin embargo su centralidad también hace que muchos lo usen por necesidad, es decir, por los usos prácticos del lugar y sus cualidades físicas. Cabe destacar que lo anterior es posible durante el día ya que en la noche la configuración es otra, se vuelve un lugar violento y lleno de borrachos acorde al imaginario de algunos agentes. Aun así pueden estar tranquilos y convivir, además su centralidad permite la movilidad a cualquier parte, tornándose muy accesible (física y económicamente). Esa centralidad es compartida por la mayoría de los agentes y, más allá de ser el centro histórico, es centro de servicios, de compras, de rutas (municipios vecinos) y también turístico. Además, es un punto de encuentro y de descanso entre los diversos agentes, especialmente en la zona donde no están los bares, ya sea por trabajo, esperando a alguien o algo, comiendo el almuerzo o aprovechando el receso del trabajo. Aunque exista una diferencia en la percepción del lugar, los que acuden saben a lo que van y qué esperan encontrar, lo que hace que se identifiquen entre ellos.

En la Plazuela del Zacate resaltan algunos elementos que nos hicieron repensar el papel de este espacio dentro del espacio público en la ciudad de Cuernavaca, factores que se puede también trasladar a otras latitudes geográficas. La centralidad de la Plazuela, su conexión con el Zócalo y el valor de la historia que de esta emana, lo convirtió en un atractivo para el poder político, construido como un recurso turístico para reproducción del capital. Como lugar central, físicamente y simbólicamente fue arrastrando una serie de reconversiones urbanísticas que la identifican actualmente como un lugar de copas y borrachos, pero que está "bonita". Su cambio fue fuerte, ya que la plazuela era el lugar donde llegaban los vendedores a vender zacate, pasó de ser conocido por la venta de flores y de vivencia popular a ser tanto un lugar para el público mayoritariamente joven, 
influido por la presencia de los bares y como un lugar turístico, hecho que se puede apreciar en la nota de Diario de Morelos "Tiene fama la Plazuela del Zacate" (Diario de Morelos del día 9 de noviembre de 2012 en línea: http:// www.diariodemorelos.com/article/tiene-famala-plazuela-del-zacate)

El poder político hace uso de esa imagen exterior como un recurso para el turismo y por esa razón apoya las sucesivas recalificaciones urbanas "ya que está en el circuito del turibus", hay que poner "bonito" y reproducir una imagen que se asemeja a contextos de ciudades nacionales o incluso internacionales focalizadas al turismo, aun cuando para ellos es igualmente un lugar de borrachos. Esa transformación hace que las personas mayores, sobre todo las que nacieron en el centro, ya sea que vivan ahí o no, tengan una imagen de un lugar que ya no existe y que se ha perdido, acorde a su experiencia y percepción, mientras que para los jóvenes es un espacio muy bueno, de identidad y de relación con los suyos. Esa transformación que diversos entrevistados refieren como algo con la cual no se identifican y que está indicada para un público blanco es el resultado de una estrategia política que se pudo identificar a partir del uso, transformación, percepción y apropiación por parte de los agentes entrevistados. La Plazuela se ha construido a partir de determinantes económicas ya que la frecuencia de visita se debe sobre todo a los bares, lo que hace que algunos entrevistados se sientan autoexcluidos en la plazuela, por este reemplazamiento de los agentes a través de la transformación que busca un lugar "boutique" en los términos de Carrión (2012).
No obstante esta forma directa de intervención política, los gobiernos tienen otros mecanismos de reproducción del capital en sociedad con empresas privadas, lo que ha fomentado las diferencias sociales en el espacio urbano de la ciudad: el consumo y la exclusividad se despuntaron en Plaza Cuernavaca. En Plazuela del Zacate hace falta mejorar la basura y los bares, en Galerías: "(...) hacen falta tiendas que desafortunadamente solo hay en México, (...) no existe por ejemplo una tienda Armani, no existe una tienda Vuitton, no existe una tienda de marcas prestigiadas que yo creo que sea conveniente que existirán en una plaza aquí en Cuernavaca" (Hombre, 33 años, Colonia Buena Vista, Licenciatura). Lo que puede representar un lugar es necesariamente diferente para los distintos agentes, pero casi siempre hay una asociación con un valor económico: mientras hacen falta marcas como Armani y solamente se le ve un valor comercial (o posiblemente dependiendo de la clase social y de lo que ha alcanzado puede ser un elemento más comercial, de prestigio o ascensión social), para otros es un lugar muy caro, pero no deja de ser un lugar de distracción y de paseo familiar.

Lo anterior en palabras de Fiske (1989) es porque el consumo no es necesariamente evidencia de deseo de poseer, sino más bien un indicio de la necesidad de control que el sistema económico niega a los subordinados, se da así la práctica del vitrineo como una forma de insertarse en el orden social, de acercarse a una clase social a la que sabe que no se pertenece, la presencia en el lugar genera la idealización de algo que no existe. Esto es lo que define metafóricamente Brummett (1994) al decir que cada uno asume una posición en lugares como Galerías y uno 
se asume como comprador o, como decía un entrevistado: "parte de la borregada", aunque no compre nada.

¿Pero será que visitar Galerías es una de las maneras de hacer y practicar ciudad (Cornejo, 2007)?, ¿cómo este lugar puede asimilar la vivencia de un contexto urbano como el centro de la ciudad o incluso de las periferias?, ¿cómo se representa este espacio en comparación con la Plazuela?

Galerías Cuernavaca es un lugar caracterizado principalmente por la práctica de consumo de las clases media y media-alta y de trabajo para los pocos de clase baja. No es un espacio donde se promueva la interacción social, solamente se reúnen pequeños grupos o familias que lo acuerdan de antemano. Al contrario de lo que menciona Cornejo (2006) en relación a los centros comerciales, Galerías no ha pasado de ser un lugar anónimo a un territorio construido, apropiado e íntimo. Es un lugar hostil, porque es clara la demarcación social (incluso fue donde los entrevistados hablaron más de clase social) incluso para los agentes que comparten la misma percepción, ya que no se extendían a hablar del lugar, simplemente respondían está "bien".

Se habla del lugar pero no como una experiencia propia, más bien como la experiencia del otro, pues quienes tienen dinero sí se identifican, ellos sí pueden acceder, pueden comprar porque tienen dinero. Esa puede ser una función de Galerías, no solo satisfacer necesidades individuales a través del consumo, sino relacionar a los agentes con un orden social que determina su posición en el lugar. No es un lugar donde existan actividades culturales, nada más comer, comprar e ir al cine, entonces no es totalmente acertado considerar que las actividades culturales que antes se hacían en la plaza pública se hayan recluido en los centros comerciales cerrados, convirtiéndose en una mercancía a la venta, donde la cultura existe en forma de experiencia mercantilizada como lo define Rifkin (2000).

Entre la representación del espacio público en el imaginario de los agentes y lo que debería ser existe un abismo, porque Galerías es considerado un lugar para todos, de libre acceso, donde todos pueden acceder libremente sin tener que pagar, sin diferencia de clase, es decir, el polo opuesto de lo que pasa en realidad en el espacio. Pero cuando se cuestiona cómo debería ser, justo debería ser como Galerías, esto es, de alguna forma existe una reivindicación de espacios públicos como Galerías aunque sus características o los elementos que lo componen no se cuajen a esta tipología. Existe la necesidad de estos espacios exclusivos posiblemente para que no exista mezcla social.

Por otro lado, su construcción privada ya demarcaba su constitución social, su difícil accesibilidad está pensada para usuarios con coche y en un área de expansión urbana de oficinas y servicios. A esta relación de accesibilidad se entrelaza la movilidad y centralidad, ya que Galerías es un lugar céntrico para los usuarios, así que una vez más podemos inferir que existen tantas centralidades cuantas necesidades y formas de desplazamiento de los diversos agentes, lo que hace diferencias de agentes entre la semana y fin de semana, entre los locales y los que vienen de fuera. 
Es un espacio multifuncional como lo define López Levi (1997), ya que la mayoría lo usa con diferentes intenciones. Pero esa multifuncionalidad de prácticas de uso no es compartida por todos los agentes debido a que la condición social es una limitante en acceso a las tiendas o hasta en el mismo espacio. Es un lugar de la familia, del paseo familiar, elemento difícil de entender con la sobrevigilancia que existe en el espacio con reglas claras de uso. ¿Será que el factor control se entiende a partir de lo que debe ser la familia, como algo controlado de jerarquización patriarcal, con límites bien definidos? Su configuración territorial hace que muchos la usen porque saben lo que los espera: el ser un espacio semipúblico les da el derecho a no ser incomodados, a la exclusividad, donde uno encuentra todo lo que busca, lo que uno necesita. Pero, ¿será que todos necesitan lo mismo? Esa imagen de exclusividad hace idealizar un espacio patrón que responde a determinada clase social y por eso tiene buena imagen, pero no resulta cómodo porque hacen falta bancas y más espacio.

Es claro que Galerías Cuernavaca está construido en respuesta al capital y como un proceso de diferenciación social, tanto para los que a ella asisten como aquellos que no acceden o no se sienten identificados con el lugar. Es un espacio cerrado sobre sí mismo y también sobre la ciudad, no existe una conexión con la estructura urbana de la ciudad, o mejor dicho, no existe con ciertos lugares de la ciudad. Pero el capital no se reproduce solamente en espacios como Galerías, también necesita de otros espacios como el Parque Cricri. "Sinceramente hay de parques a parques y este es el que tiene más corrupción, pero el parque es de todos y una vez dentro es una ciudad sin ley, aquí he visto personas que se drogan, toman y lo demás no se lo digo por discusión, pero hay de todo"(Hombre, 43 años, Colonia Buena Vista, Primaria).

Hablar del Parque Cri-cri después de Plazuela del Zacate y Galerías Cuernavaca es hablar de un lugar muy distinto, si puede decirse así, de un verdadero "lugar" público en el sentido de las funciones tradicionales como esparcimiento, distracción, descanso, juego, entre otros, pero también de un lugar en el sentido de Massey (2005). Este es un lugar fundamental para el bienestar físico y psíquico de los agentes porque es un espacio donde se puede olvidar el trabajo, la rutina del día a día; donde se encuentra tranquilidad, donde es posible relajarse, distraerse, jugar, en una palabra, cumplen con la función tradicional de un lugar público, de un parque público. Por otro lado, este lugar también es una forma de subsistencia ya que muchos hombres buscan a diario ahí trabajo y hay quien trabaja directamente en el parque. ¿Qué nos dice el Parque Cri-cri? Este lugar en un contexto urbano es mucho más que un espacio de "cohesión social" o de estructuración de la red urbana, es un lugar donde la gente busca trabajo para poder sobrevivir y eso va más allá de lo que se conoce del espacio público.

Para las personas que ahí buscan trabajo, el concepto de espacio público seguramente es muy diferente y para nada un espacio de integración social o regeneradora del tejido social. El parque Cri-cri es un lugar que desde la perspectiva física se encuentra descuidado, además, no es apropiado, hay mucho mal viviente, hombres con mal aspecto, drogadictos, hay peleas, los policías tratan 
mal a los jóvenes y fue tomado por las mujeres prostitutas. Curiosamente, no deja de ser un lugar al cual acuden familias y el monumento Escultura de Gabilondo Soler representa la familia: bonito, tranquilo, que está bien, un lugar fresco por los árboles y el viento. Esto nos lleva a considerar que el uso no tiene una implicación directa con la percepción, no se usa como se percibe y las características físicas del lugar no condicionan el uso. Lo que sí condiciona es la forma como se apropian los distintos grupos del lugar: el modo como se distribuyen en el espacio determina una jerarquía o una forma de poder que legitima un grupo y excluye al otro y así sucesivamente. El comportamiento y las características del grupo crea de manera conjunta determinado estigma en relación a los mismos y eso se percibe pero no hace que los demás dejen de usar, porque el mismo lugar tiene demasiados lugares. El parque funciona como uno solo, porque aunque hay diferencias entre grupos, el parque es de todos; sin embargo se cuestiona el otro, no se aleja. El Parque Cri-cri es el centro de la ciudad, forma "parte" del centro de la ciudad, del Zócalo, al cual se acede fácilmente, se encuentra entre dos paradas de rutas importantes con servicio a cualquier parte, sobre todo a los municipios vecinos. Además, se encuentra cerca del Mercado López Mateos, factor importante considerando que la mayoría frecuenta el mercado o trabaja en él. Así, la centralidad de un lugar no depende de su centralidad histórica sino de su accesibilidad y cercanía con los distintos servicios, de las necesidades de cada uno y de un grupo social con necesidades específicas, es decir, nadie en Galerías va al Mercado López Mateos a comprar.
Curiosamente, y en oposición a Galerías, donde todo apuntaba para que los agentes se sintieran cómodos, eso no pasó, pero en Cri-cri casi todos se sienten bien, se sienten cómodos, aun cuando tiene mala imagen provocada por descomposición física y social del lugar. La forma de relación con el parque es muy personal pero también de grupo, porque un aspecto relevante de esta cuestión es que todos hablaban de su experiencia personal en primer persona, hecho que no ocurrió en los demás espacios. Por otro lado, hay algo que los une e identifica, la clase social, y posiblemente eso hace que en Cri-cri sea fácil platicar y conocerse, que sea posible una relación entre amistades y conocidos a partir de la frecuencia e intención de uso, sea esta buscar trabajo, servicios de las prostitutas o droga: "Sí, por lo mismo de que somos de la clase baja económicamente hablando y sin estudio. Aquí no hay hijos de Adame o Garrigós" (Hombre, 45 años, Colonia Chipitlán, Primaria)

Es importante mencionar que los tres lugares de análisis tienen públicos muy distintos, fue interesante analizar cómo se veían los unos a los otros y constatar que no existe una relación de cercanía entre ellos. Cada grupo se mueve de acuerdo a su condición social, sus necesidades y su centralidad, no significa que estos espacios sean nuevas centralidades, sino que las insuficiencias de cada grupo, su movilidad y accesibilidad a los lugares es lo que hace céntrico a un lugar. Esa movilidad también representa una alienación frente a la ciudad porque muchos no tienen conocimiento de lo que está ocurriendo en los espacios de vida de todos, tienen un conocimiento fragmentado de la ciudad, pero saben que los gobiernos Municipal y Estatal 
trabajan en función de la clase alta, dejando en el olvido las "colonias".

Así, estamos frente a espacios públicos definidos por las prácticas de los agentes que los usan, factor muy distinto a lo establecido en las diferentes posiciones académicas y políticas. Si para los agentes entrevistados el espacio público es un lugar de trabajo, diversión, descanso, familia y un lugar que marca la diferencia entre ricos y pobres, para el poder político es el espacio ciudadano en el que se reproduce una imagen urbana a partir de una homogeneización idealizada que agudiza la diferenciación social y cuyo embellecimiento permite controlar socialmente la ciudadanía. ${ }^{11}$ En este contexto, ¿es correcto seguir hablando de espacio público como un concepto universal y transversal a todas las latitudes geográficas?

\section{El espacio público de Cuernavaca es...}

“ ¡Yo ya no sé qué es un espacio público ya todo está controlado por los políticos!". Las prácticas de uso, apropiación y percepción en los espacios públicos de la Ciudad nos han llevado a creer que el espacio público no existe como lo han replanteando diversos estudios, pero sí lugares. Si el análisis de espacios públicos concretos nos alertó para esta cuestión, cuando se preguntó a los agentes qué era un espacio público y cómo debería ser, esta alerta se convirtió en una afirmación que lleva a reconocer el espacio público como un lugar, producto de una mezcla distinta de todas las relaciones, prácticas, intercambios (entre diferentes agentes) y que se entrelazan en él. Además en su construcción, todas esas relaciones y prácticas y todos los intercambios, están llenos de poder social. Son relaciones de poder las que se dan en esos lugares al mismo tiempo que resulta en una arena de legitimación social de los poderes políticos. Este Lugar es un entretejido de relaciones sociales, en algunas de ellas el lugar tendrá una posición subordinada, mientras que en otras tiene una posición más o menos dominante; es una apuesta política de las clases emblemáticas de la ciudad para lucirse. Además, son lugares de la multiplicidad, construidos por la lucha de poder y control social que marca la diferenciación social, y finalmente está siempre abierto, siempre en construcción, nunca está acabado.

Para los agentes, el espacio público es sobre todo un lugar, un lugar a veces abstracto donde existe una confusión en relación a lo que es pero no a cómo debería ser. Los agentes no reconocen en el concepto las características de un espacio público, pero si de un Lugar o de Lugares, aun cuando esa relación puede ser conflictiva. Ese lugar en el Parque Cri-cri es el mismo parque y debe permitir la inserción en el mercado laboral, cubrir las necesidades básicas de los agentes (agua y baños), permitir el descanso, el usufructo del fresco de la vegetación, que uno se sienta libre y que sea de todos.

En la Plazuela del Zacate, un espacio público también es un Lugar, un lugar accesible y disponible a todos, para toda clase de gente, que no haya presiones, en el cual se puede uno despreocupar, estar a gusto, donde se puede convivir con la familia. Debe ser para todos sin distinción, para niños, limpio, muy bonito, con flores, muy amplio 
donde predomine el verde. Curiosamente, en Galerías Cuernavaca el espacio público también es un Lugar para todo tipo de gente, es libre, no cobran, es de todos sin restricciones y sin diferencia de clase, pero debe de ser sobre todo como Galerías. Así, Galerías no es un espacio público pero lo debe ser porque hay que tener lugares de exclusión, donde la pertenencia de clase sea un marcador social.

Son las especificidades de estos espacios lo que los hacen lugares, construidos a partir de "una constelación determinada de relaciones sociales, encontrándose y entretejiéndose en un sitio particular" (Massey, 2012, p. 112), donde los agentes ocupan distintas posiciones. Pero también porque es "el lugar en el que el Estado logra desmentir momentáneamente la naturaleza asimétrica de las relaciones sociales que administra y a las que sirve y escenifica el sueño imposible de un consenso equitativo en el que puede llevar a cabo su función integradora y de mediación" (Delgado, 2011, p. 28), es decir, es una extensión material de lo que en realidad es ideología.

\section{Espacio público y geometrías del poder}

La forma de las relaciones socioterritoriales de los espacios públicos de Cuernavaca está determinada por múltiples factores, especialmente por la clase social y la capacidad con que el poder político territorializa en los lugares esa diferencia de clase a partir de diversos mecanismos de intervención urbana y de control social. Uno de esos mecanismos es el control por la movilidad que refuerza el poder, debilitando otros grupos. El debilitamiento hace que cada grupo se mueva de acuerdo a su condición social y sus necesidades, lo que genera distintas centralidades.

[...] la movilidad y el control por la movilidad reflejan y refuerzan el poder. No se trata de una mera cuestión de distribución desigual y de que algunas personas se muevan más que otras. Se trata de que la movilidad y el control de algunos grupos pueden debilitar activamente la de otra gente. La compresión espacio-temporal de unos grupos socava el poder de otros. (Massey, 2012, p. 119).

El modo en que los agentes determinan sus prácticas en los lugares no es neutro, refleja su condición a partir de cómo fue pensado el lugar y a quién se espera que responda. Existen objetivos claros del poder político en la consolidación de lugares con perfiles diferenciados, porque hay que mantener una jerarquización social y diferentes formas de anclar al capital, a través de estructuras internas de dominación y subordinación, pero también de legitimación social. En este proceso, el concepto de espacio público es un blanco ideal por su ambigüedad y carácter "democrático", encabeza las agendas políticas como un elemento ideal e idealizado que provoca la ilusión de que lo que se hace es para la integración social de todos cuando, en realidad, lo que se hace según Marx es camuflar toda la relación de explotación, todo dispositivo de exclusión y el papel de los gobiernos como encubridores y garantes de todo tipo de asimetrías sociales (Delgado, 2011). 
Una observación muy interesante que se pudo obtener del análisis comparativo es que para que un "verdadero" lugar público desarrolle las funciones de esparcimiento, diversión, relajación y juego, no siempre es condición necesaria que los poderes políticos realicen proyectos de recalificación urbana u otro tipo de intervenciones en el "espacio público". Parece ser que estas estrategias o programas de recalificación urbana impulsados desde los gobiernos locales, estales y agencias internacionales son una falacia. ¿Cómo pueden estar promoviendo este tipo de programas que no hacen más que aumentar las desigualdades sociales? Lo que parece aún ser más grave es que no es solamente en los discursos políticos sino también los académicos en donde comúnmente escuchamos hablar de la promoción de proyectos cuya finalidad es recalificar, reconvertir y recuperar determinados espacios urbanos o concretamente espacios públicos para regenerar los espacios urbanos y promover la cohesión e integración social. Las agendas políticas suman y siguen las diferentes formas de tratar este tipo de proyectos, alentando una promoción desmentida de la política "social" o responsabilidad "social" de gobiernos neoliberales.

Aunque el urbanismo tenga como objetivo promover la articulación urbana y la equidad social, la forma como se lo ha tratado no deja margen de duda de que ha sido un anclaje espacial del capitalismo. ¿Quién se está beneficiando con estas estrategias de recalificación urbana o intervención privada? Seguramente no son las clases más desfavorecidas las que alegan su condición de pobreza y su identidad con el lugar por ser de la misma clase o los que no se identifican en Galerías, pero saben que los que tienen dinero sí. Implícitamente, en los discursos que justifican los proyectos de intervención en el "espacio público" se alega el hecho de que la pérdida de sociabilización es consecuencia de la proliferación de espacios privados, pero si pensamos en el Parque Cri-cri y la Plazuela, no podemos decir que eso esté ocurriendo, son espacios de sociabilidad, de interacción social y con dinámicas fuertes al largo de los días. Además, esa pérdida de la vida pública asociada a la privatización de la vida colectiva como los centros comerciales no se adecua a la realidad de Cuernavaca, porque no se ha perdido la vida pública en los espacios públicos tradicionales, esa pérdida se siente justo en Galerías Cuernavaca donde no existe esa sociabilidad, donde cada quien está en lo suyo, donde la clase social es lo que identifica y no el encuentro, como sucede en la Plazuela o el Parque Cri-cri. Este punto puede ser una diferencia en relación a las sociedades occidentales sobre las que Sennett (1978) apuntaba un repliegue de la sociabilidad al espacio doméstico, al privado, pero no hay que perder de vista que ese "encarcelamiento" era de las clases altas, las clases bajas siguen viviendo los lugares públicos y, además, los espacios siempre fueron socialmente homogéneos.

La utilización de tres unidades de análisis tan distintas nos llevó a considerar que el espacio público no existe como tal, porque los agentes entrevistados no reconocen ese concepto para el lugar donde están desarrollando sus prácticas sociales. Además, es un concepto demasiado ambiguo que puede referirse a cosas tan distintas, con usos, significados y representaciones dentro de un 
contexto urbano tan múltiples que no se puede validar como algo que tenga una aplicación común. Aun cuando se repitan acciones como sentarse, pasear, ver, comer, la forma como se hace marca esa diferencia, porque no es lo mismo sentarse en Galerías que en la Plazuela 0 en el Parque Cri-cri.

A partir de esta reflexión y en el marco de análisis de la presente investigación resignificaremos el concepto de espacio público y asumimos el de lugar, ya que el espacio no existe en la ciudad pero sí existen lugares, lugares usados por agentes distintos que juegan papeles distintos en la ciudad, construidos a partir de determinantes específicas, conformados y estructurados por tipologías distintas y que están llenos de poder, así, es un caso para decir "La geografía importa" (Massey, 1984), porque cada lugar es un lugar.

\section{Carla Alexandra Filipe Narciso}

Becaria del Consejo Nacional de Ciencia y Tecnología - Conacyt. Ciudad de México, México. carla-narciso@iol.pt

\section{Notas}

(1) Esta idea del derecho al espacio público hizo que desde varias organizaciones e instituciones nacionales e internacionales hayan elaborado "guías" para la implementación de lo que deben ser espacios públicos de calidad que promuevan la integración social.

(2) Veamos los trabajos de Setha Low (2005) sobre Costa Rica y Michael Sorkin (2004) en que varios autores dan el ejemplo de diferentes ciudades estadounidenses.

(3) Fernández, Amin y Vigil (2008) hacen una reflexión acerca de cómo fueron cambiando las teorías del desarrollo regional y de cómo se va formando la Nueva Ortodoxia Regional como un discurso, ideas que retomamos para hacer referencia al concepto de espacio público.

(4) Considerando un proceso que se da mucho antes en otras latitudes geográficas que en la Ciudad de Cuernavaca.

(5) Toda esta estrategia del programa de embellecimiento de la imagen urbana de Cuernavaca respondió también al propósito del alcalde de especular en beneficio propio. Este creó una empresa fantasma, DCA infraestructura, que estuvo encargada de las obras, y cuando estas estuvieran concluidas, la empresa daría la manutención a los espacios de forma gratuita durante un año. Sin embargo, resulta que esa manutención va costar al ayuntamiento 7.5 mdp anuales, a partir de la conclusión de las obras.

(6) http://morelosdiario.com/index.php/destacamos/298-cuernavaca-tiene-imagen-digna-gracias-algobierno-municipal-.html 
(7) http://www.stereomundo.com.mx/index.php?option=com_content\&view=article\&id=20869: inauguran-la-fuente-de-la-eterna-primavera-y-sus-cinco-musas-en-la-avenida-teopanzolco\&catid=81:cuernavaca\&/temid $=458$

(8) La escultura es de Ricardo Ponzanelli.

(9) Ídem.

(10) Al iniciar nuestra investigación no habíamos contemplado los espacios comerciales, ya que no lo consideramos como espacio público, sino privado de acceso público (semipúblico), sin embargo en el transcurso de la investigación nos dimos cuenta de cómo estos espacios tenían una expresión muy significativa en la ciudad al mismo tiempo que se reflejaba en ellos la jerarquización de clases. Como queríamos también analizar la variedad de respuestas por clase social, tuvimos que reconsiderar los espacios comerciales y tomamos como referente Galerías Cuernavaca.

(11) Incluso se puede notar una diferencia en la forma como el poder político utiliza los conceptos, como el caso de ciudadanía. Por un lado, el espacio de la ciudadanía como el espacio de todos, de la democracia y por el otro, el espacio de la ciudadanía que debe ser controlado

\section{Referencias}

AMIN, Ash (s.d.). The politics of urban public space. Disponible en: http://es.scribd.com/maria_ zarate_1/d/40469568-Ash-Amin-Politics-of-Ubran-Space.

ARENDT, H. (1972). La crise de la culture. Paris, Ideés/Gallimard.

BORJA, J. (2003). La ciudad conquistada. Madri, Alianza.

(2005). "Revolución y contrarevolución en la ciudad global". In: HARVEY, D. e SMITH, N. (2005). Capital financiero, propiedad inmobiliaria y cultura. Barcelona, Universitat Autónoma de Barcelona/MACBA.

BORJA, J. e FORN, M. (1996). Políticas da Europa e dos Estados para as Cidades. Revista Espaço e Debates. São Paulo, n. 39, pp. 32-47.

BRENNER, N.; PECK, J. e THEODORE, N. (2009). Urbanismo neoliberal: la ciudad y el imperio de los mercados. SUR Corporación de Estudios Sociales y Educación. Temas sociales, n. 66.

BRUMMETT, B. (1994). Rhetoric in popular culture. Boston, Bedford/St. Martin's.

CALDEIRA, T. (2007). Ciudad de muros. Barcelona, Gedisa.

CARRIÓN, F. (2007). "Espacio público: punto de partida para la alteridad”. In: SEGOVIA, O. Espacios públicos y construcción social. Hacía un ejercicio de ciudadanía. Santiago de Chile, SUR.

(2012). "Dime quién financia el centro histórico y te diré qué centro histórico es". In: ZICCARDI, A. (coord.). Ciudades del 2010: entre la sociedad del conocimiento y la desigualdad social. México, Puec-Unam. 
CORNEJO, I. (2006). El Centro Comercial: ¿una nueva forma de "estar juntos"? Revista Cultura y representaciones sociales, año $1, \mathrm{n} .1$.

(2007). El lugar de los encuentros, comunicación y cultura en un centro comercial. México, Universidad Iberoamericana.

DAVIS, M. (1992). Planeta de ciudades miseria. Madri, Foca.

DELGADO, M. (2011). El espacio público como ideología. Madri, Catarata.

DGOTDU - Direcção Geral do Ordenamento do Território e Desenvolvimento Urbano (2008). $A$ identidade dos lugares e a sua representação colectiva. Bases de orientação para a concepção, qualificação e gestão do espaco público. Série Política de Cidades, 3.

DIARIO DE MORELOS (9/11/2012). Disponível em: http://www.diariodemorelos.com/article/ tienefama-la-plazuela-del-zacate. Acesso em: 23 nov 2013.

DUHAU, E. (2003). "Las megaciudades en el siglo XXI. De la modernidad inconclusa a la crisis del espacio público”. In: RAMíREZ KURI, P. (2003). Espacio público y reconstrucción de la ciudadanía. México, Flacso/Miguel Ángel Porrúa.

DUHAU, E. e GIGLIA, A. (2008). Las reglas del desorden: habitar la metrópoli. México, UAMAzcapotzalco/ Siglo XXI.

FAINSTEIN, S. (1994). The city builders. Cambridge, Blackwell.

FISKE, J. (1989). Reading the Popular. Londres/Nova York, Routledge/Unwin Hyman.

GIGLIA, A. (2003). “Espacio público y espacios cerrados en la ciudad de México". In: RAMíREZ KURI, P. Espacio público y reconstrucción de la ciudadanía. México, Flacso/Miguel Ángel Porrúa.

HABERMAS, J. (1984). Mudança estrutural da esfera pública. Rio de Janeiro, Tempo Brasileiro.

HARVEY, D. (2007). Breve história del capitalismo. Madri, Akal.

JACOBS, J. (1992). The death and life of the great american cities. Nova York, Vintage.

LEFEBVRE, H. (1974). The production of space. Oxford, Blackwell.

LEITNER, H.; PECK, J. e SHEPPARD, E. (eds.). (2007). Contesting neoliberalism: urban frontiers. Nova York, Guilford.

LÓPEZ LEVI, L. (1997). Los centros comerciales como espacios multi funcionales. Argumentos, n. 27, pp. 81-96.

LOW, S. (2005). Transformaciones del Espacio Público en la Ciudad Latinoamericana: cambios espaciales y prácticas sociales. Bifurcaciones, n. 5. Disponível em: www.bifurcaciones.cl/005/ Low.htm. Acesso em: 16 abr 2007.

MASSEY, D. e ALLEN, J. (1984). Geography matiers, a reader. Cambridge University.

MASSEY, D. (2005). "La filosofía y la política de la espacialidad: algunas consideraciones”. In: ARFUCH, L. (comp.). Pensar este tiempo: espacios, afectos, pertenencias. Buenos Aires, Paidós. (2008). Pelo espaço. Brasil, Bertrand.

(2012). "Un sentido global del lugar". In: ALBET, A. e BENACH, N. Doreen Massey. Un sentido Global del lugar. Barcelona, Icaria. 
PORTAS, N. (2003). "Espaço público e cidade emergente". In: BRANDÃO, P. e REMESAR, A. Design e espaço público, deslocação e proximidade. Lisboa, Centro Português de Design.

PRADILLA, E. (2009). Los territorios del neoliberalismo en América Latina. México, UAM-X/Miguel Ángel Porrúa.

RAMíREZ, B. (2010). "De la ciudad global a la ciudad neoliberal. Una propuesta teórica y política”. In: ALFIE, M.; AZUARA, I.; BUENO, C.; PÉREZ NEGRETE, M. e TAMAYO, S. (eds). Sistema mundial y nuevas geografías. México, UAM-Azcapotzalco, UAM- Cuajimalpa y UIA.

RAMíREZ KURI, P. (2009). Espacio público y ciudadanía en la ciudad de México. Percepciones, apropiaciones y prácticas sociales en Coyoacán y su centro histórico. México, UNAM-IIS. PUEC/ Miguel Ángel Porrúa.

RIFKIN, J. (2000). La era del acceso: la revolución de la nueva economía. Barcelona, Paidós.

SANTOS, M. (1986). Espacio y Método. Geocritica. Cadernos Críticos de Geografia Humana. Barcelona, Publicacions i Edicions UB, n. 65.

SENNETT, R. (1978). El declive del hombre público. Barcelona, Anagrama.

SMITH, N. (2005). "Capital financiero, propiedad inmobiliaria y cultura”. In: HARVEY, D. e SMITH, N. Capital financiero, propiedad inmobiliaria y cultura. Barcelona, Universitat Autónoma de Barcelona/MACBA.

SORKIN, M. (ed.) (2004). Variaciones sobre un parque temático, la nueva ciudad americana y el fin del espacio público. Barcelona, Gustavo Gili.

ZUKIN, S. (2010). Naked city. The death and life of authentic urban places. Nova York, Oxford.

Texto recebido em $11 /$ set/2013

Texto aprovado em 23/dez/2013 
